\title{
Partial Sphingomyelinase Deficiency with Sea-Blue Histiocytosis and Neurovisceral Dysfunction
}

\author{
Masaaki KOnAGAYA, Toshihiko KONISHI, Yoko KONAGAYA, \\ Tetsuya TAKAYANAgI, Etsuko KITA* and Tatsuro Muto**
}

\begin{abstract}
A case of partial sphingomylinase deficiency with supranuclear vertical ophthalmoplegia, perceptive hearing loss and renal failure is reported. Extensive studies revealed sea-blue histiocytosis in bone marrow, delayed peripheral nerve conduction velocity, selective IgG and IgM deficiency, mild hepatosplenomegaly and testicular hypotrophy and retention. Although renal failure, perceptive deafness, immunoglobulin deficiency and testicular malformation are rare conditions in sphingomyelinase deficiency, this case mimicked to lipidosis reported by Neville. The association of congenital malformation and uremia might accentuate the symptoms.
\end{abstract}

Key words: Sphingomyelinase deficiency, Vertical ophthalmoplegia, Alport syndrome, Immunoglobulin deficiency, Testicular hypotrophy, Sea-blue histiocytes.

Niemann-Pick Disease (NPD) is a neurovisceral sphingomyelin storage disease, in which accumulation of sphingomyelin and sphingomyelinase deficiency are pathognostic. Besides the Crocker's 5 types (1), a peculiar variant was reported by Neville (2), the clinical characters of which are supranuclear ophthalmoplegia, hepatosplenomegaly and sea-blue histiocytes in bone marrow with or without partial deficiency of sphingomyelinase (3). This form of lipidosis has been reported to show various symptoms (2-8). We describe a case of partial sphingomyelinase deficiency associated with vertical ophthalmoplegia, renal failure, sensory deafness, $\mathrm{IgG}$ and IgM deficiency and testicular hypogenesis.

\section{CASE REPORT}

A 13-year-old boy came to our clinic to be examined neurologically for abnormal eye movement.
His delivery was normal and body weight at birth was $3,050 \mathrm{~g}$. In spite of normal development in his infancy, his mother noticed hearing disturbance at age 2 , which progressed to be complete hearing loss at age 10. At age 7, proteinuria, hypogammaglobulinema and testicular disorders were pointed. The renal biopsy at that time showed increased matrix of mesangium, no increase of mesangium cell and normal Bowmann's capsule, renal tubule and blood vessel. His renal function gradually worsened to fall into uremia at age 9 , which was followed by hemodialysis treatment. There was no family history of the similar disease.

The physical examination revealed short statue of $120 \mathrm{~cm}$ height and $20 \mathrm{~kg}$ of weight, anemic conjuctiva and dry skin. There was no hepatosplenomegaly. His left testis was pea size, and right one was retentio testis. His mentality was normal of IQ 123. In spite of no diplopia nor nystagmus, the up-

From Department of Neurology and *Department of Clinicolaboratory Diagnostics, Nara Medical University, Kashihara.

**The Second Department of Medicine, Fukui Medical School, Fukui.

Received for publication May 25, 1988.

Reprint request to: Masaaki Konagaya, MD PhD. Department of Neurology, Nara Medical University, 840 Shijo cho, Kashihara, Nara 634, Japan 
ward gaze was severely, and downward gaze was moderately limited. The doll's eye phenomenon was preserved. He showed bilateral perceptive deafness. Motor function, muscle stretch reflex, coordination and sensation were all normal. Cherry-red spots was not found with fundoscopic examination.

Peripheral blood count was red cell $291 \times 10^{4} / \mathrm{cmm}$, hemoglobin $8.6 \mathrm{~g} / \mathrm{dL}$, white cell $5800 / \mathrm{cmm}$. Total protein was $6.6 \mathrm{~g} / \mathrm{dL}$ and $5.3 \%$ gamma globulin (IgA $133.5 \mathrm{mg} / \mathrm{dL}, \operatorname{IgG} 446.8$ $\mathrm{mg} / \mathrm{dL}$, IgM $46.7 \mathrm{mg} / \mathrm{dL}$ ). The complements were normal. Before the hemodialysis, BUN was 102 $\mathrm{mg} / \mathrm{dL}$ (after the dialysis, 40), uric acid $8.0 \mathrm{mg} / \mathrm{dL}$ (3.2), creatinine $8.2 \mathrm{mg} / \mathrm{dL}$ (3.9), $\mathrm{Na} 133 \mathrm{mEq} / \mathrm{dL}$ (140), P $8.0 \mathrm{mg} / \mathrm{dL}$ (3.0), $\mathrm{Mg} 2.7 \mathrm{mg} / \mathrm{dL}$ (3.0). Betalipoprotein was $656 \mathrm{mg} / \mathrm{dl}$, total cholesterol 233

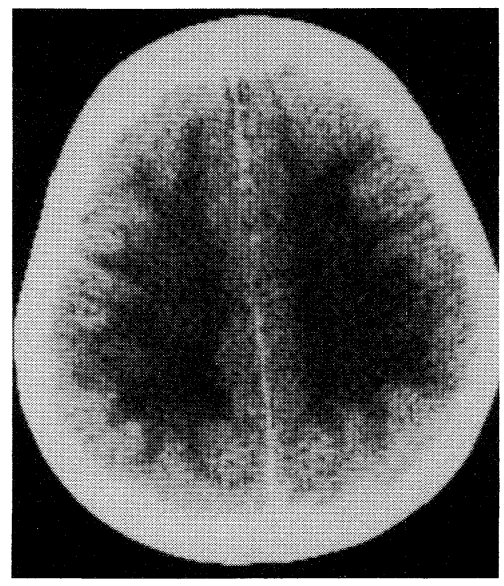

Fig. 1. Brain CT demonstrated extremely low intensity in white matter.

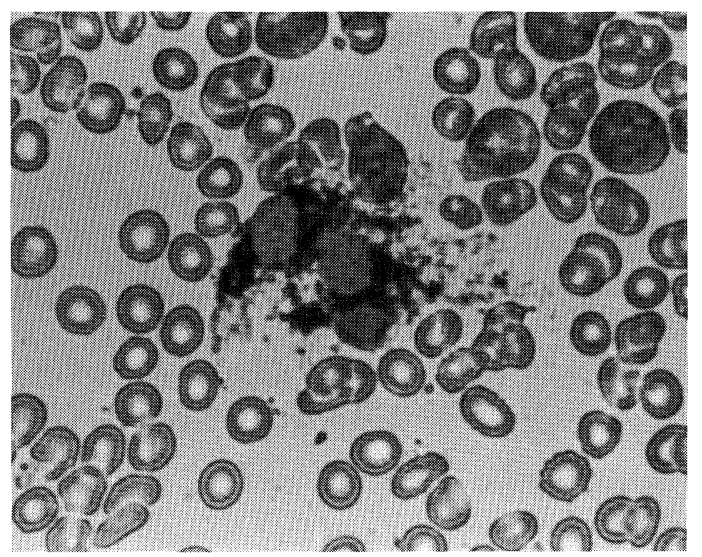

Fig. 2. Sea-blue histiocyte in bone marrow. MayGiemsa's stain. $\times 400$. $\mathrm{mg} / \mathrm{dl}$, neutral lipid $93 \mathrm{mg} / \mathrm{dl}$, phospholipid 235 $\mathrm{mg} / \mathrm{dl}$. Serum hormonal examination showed elevated $\mathrm{LH}(>500 \mathrm{mIU} / \mathrm{ml})$ and $\mathrm{FSH}(>500$ $\mathrm{mIU} / \mathrm{ml})$ as well as low level of testosterone $(0.6$ $\mathrm{ng} / \mathrm{ml}$ ). The chromosome type was $46 \mathrm{XY}$. X-ray CT showed diffuse low density of cerebral white matter (Fig. 1). EEG findings were 7-8 Hz and 80 $\mu \mathrm{V}$ amplitude of basic rhythm with burst discharges of sharp wave and $3 \mathrm{~Hz}$ slow wave. The motor nerve conduction velocity was $46.4 \mathrm{~m} / \mathrm{sec}$ at right median nerve and $35.7 \mathrm{~m} / \mathrm{sec}$ at right tibial nerve, respectively. The sensory nerve conduction velocity was also slightly decreased (r-median nerve $46.2 \mathrm{~m} / \mathrm{sec}$, $\mathrm{r}$-sural nerve $40.0 \mathrm{~m} / \mathrm{sec}$ ). The sea-blue histiocytes were observed in bone marrow (Fig. 2). The activity of sphingomyelinase in peripheral blood lymphocyte (3) was reduced to $3.84 \mathrm{u}$. (mean normal value 5.77 $\mathrm{u}$, range 4.23-6.78 u). Other lysosomal enzyme activity were normal; alpha-mannosidase $45.6 \mathrm{u}$. (normal range; 27.3-53.2), alpha-fucosidase $30.5 \mathrm{u}$. (11.4-34.9), beta-galactosidase $194.8 \mathrm{u}$. (165.8-321.6), beta-hexosaminidase $280.4 \mathrm{u}$. (117.6-374.8).

At age 15, he had a convulsion attack which began from right arm and generalized to the whole body, and his blood pressure elevated to 212-104 $\mathrm{mmHg}$. He came to our clinic the next day of the fit. His height was $140 \mathrm{~cm}$ and body weight was 30 $\mathrm{kg}$. The hepatic edge was palpable $1 \mathrm{~cm}$ below the costal margin, and splenic tip $2 \mathrm{~cm}$. The development of the second sexual character was poor. The neurological examination showed no significant change compared with the previous examination.

\section{DISCUSSION}

The present case has been involved both in central and peripheral nervous system as well as urinary, endocrine and immune systems. Extensive studies revealed sea-blue histiocytes in the bone marrow, low density of cerebral white matter in CT and reduced activity of sphingomyelinase, which indicated that he suffered from sphingomyelin lipidosis. The association of congenital malformation and uremia which required hemodialysis may accentuate these symptoms.

Neville and his colleague reported 13 cases of a neurovisceral lipid storage disease with vertical 
supranuclear ophthalmoplegia, sea-blue histiocytes and accumulation of sphingomyelin in the spleen (2). In that report, most cases showed ataxia, extrapyramidal signs and dementia with epilepsy. Other neurological symptoms reported by several authors were catalepsy (6), perceptive hearing loss $(5,8)$ and neurogenic bladder $(6,8)$, and the onset of these neurological deteriorations were in childhood. There is an argument whether this lipidosis is a variant of NPD or not, because decrease of sphingomyelinase activity is uncertain (3). In the present case, clinical and laboratory findings were similar to those of Neville's lipidosis, however, the followings were peculiar; mild involvement of the central nervous system, mild hepatosplenomegaly, renal failure, IgG and $\mathrm{M}$ deficiency and testicular malformation.

The decreased density of white matter in brain CT was observed, but we could not find any neurological signs except perceptive hearing loss, ophthalmoplegia and convulsion. The perceptive hearing loss was often reported, and a brainstem auditory evoked test revealed prolongation of waves I-III in clinically normal hearing cases of Crocker's type A (9), acute infantile neurovisceral form, and type C NPD (10), mild neurovisceral form. The convulsion is an occasional neurological symptom in NPD. The present case also had a convulsion attack, but it is unclear whether this fit was due to lipidosis or dysequilibrium syndrome for hemodialysis (11).

The peripheral nerve involvement has also been reported in NPD. Delayed peripheral nerve conduction velocity (9), the cytoplasmic body in Schwann cell $(12,13)$ and segmental demyelination (13) were reported in cases of type A NPD. A case of type $\mathrm{C}$ also showed the same pathological change as above (14). On the other hand, in a case of Neville's type lipidosis, accumulation of autofluorescent lipopigment in Schwann cell was observed by Kornfield (7). We could not perform sural nerve biopsy, but the delayed peripheral nerve conduction velocities indicated a subclinical peripheral neuropathy. Peripheral nerves seem to be often involved in NPD, and there might be a number of preclinical conditions. Hemodialysis or uremic state (11) may accentuate the peripheral nerve dysfunction associatd with lipid metabolic disorder in this case.

Hypogammaglobulinemia and testicular hypogenesis were also characteristic to the present case. Selective $\operatorname{IgA}$ deficiency associated with Crocker's type B NPD, non-neuronopathic visceral form, was reported (15), and the latter condition was observed in a feline sphingomyelin lipidosis (16). But it is uncertain as to the relationship between these conditions and sphingomyelinase deficiency.

Although hepato-splenomegaly, which is mild in the present case, is a common visceral finding, renal failure is rare in sphingomyelin storage disease. The excess of sphingomyelin with normal histology in kidney was reported in a case of NPD by Burne (7). Foamy cytoplasmic reticular endothelial cell was reported in Crocker's type B NPD $(18,19)$ and feline sphingomyelin lipidosis (16). A case of type B showed elevated BUN and lipid laden macrophage in kidney with hyperimmuno-globulinemia and deposition of immune complex in the glomerular basement membrane (18). But, the present case was different from this condition because of hypogamma-globulinemia. The association of renal failure and perceptive deafness in early childhood might suspect this case of Alport syndrome (20). The renal morphological changes of this syndrome are mild cellular infiltration and mild increase of matrix in mesangium in early stage, and generalized glomerulonephritis with foamy cell in later stage. The renal biopsy finding of the present case at age 7 is non-specific but similar to that of early stage of Alport syndrome. It is difficult to say whether or not renal failure in this case is merely concomitant of the lipidosis, but it is interesting that the renal foamy cell is observed both in Alport syndrome and sphingomyelinase deficiency.

This case showed a wide variety of signs. Some are considered to be symptoms of NPD, and others seem to be indistinctive to the disease. The association of hypogammaglobulinemia, testicular hypotrophy and renal failure with NPD is a rare condition, which hints a causalty, and might accentuate the original symptoms similar to Neville's type lipidosis.

\section{REFERENCES}

1) Crocker AC: The cerebral defect in Tay-Sachs disease and Niemann-Pick disease. J Neurochem 7: 69, 1958.

2) Neville BGR, Lake BD, Stephens R, et al: A neurovisceral storage disease with vertical supranuclear. 
ophthalmoplegia, and its relationship to Niemann-Pick disease. Brain 96: 97, 1973.

3) Wenger DA, Barth G, Githen JH: Nine cases of sphingomyelin lipidosis, a new variant in SpanishAmerican children - Juvenile variant of Niemann-Pick disease with foamy and sea-blue histiocytes. Am J Dis Child 131: 955, 1977.

4) Breen L, Moris $\mathrm{HH}$, Alperin JB, et al: Juvenile Niemann-Pick disease with vertical supranuclear ophthalmoplegia - two case reports and review of literature. Arch Neurol 38: 388, 1981.

5) Dunn HC, Sweeney VP, Vancouver BC: Progressive supranuclear palsy in an usual juvenile variant of Niemann-Pick disease. Neurol 21: 442, 1971.

6) Kandt RS, Emerson RG, Singer HS, et al: Catalepsy in variant forms of Niemann-Pick disease. Ann Neurol 12: 284, 1982.

7) Konfeld M, Appenzellar O, Saiki J, et al: Sea-blue histiocytes and sural nerve in neurovisceral storage disorder with vertical ophthalmoplegia. J Neurol Sci 25: 291, 1975.

8) Machi M, Tabira $T$, Shibasaki $H$, et al: Lipidosis with vertical gaze palsy, macular degeneration, and sphingomyelinase deficiency. Clin Neurol 22: 718, 1982.

9) Elleder M, Nevola J, Spicakova V, et al: A new variant of sphingomyelinase deficiency (Niemann-Pick): Visceromegaly, minimal neurological lesions and low in vivo degradation of rate of sphingomyelin. J Inherit Metab Dis 9: 357, 1986.

10) Aisen M, Rapoport S, Solomon G: Brainstem auditory evoked potentials in two siblings with Niemann-Pick disease. Brain Develop 7: 431, 1985.

11) Henderson LW: Dialysis. In: Plow F (ed) Cecil's text- book of medicine. Saunders, Philadelphia London Tront Mexico City Rio de Janeiro Sydney Tokyo, p511, 1982.

12) Guambinas M, Larsen A, Liu HM: Peripheral neuropathy in classic Niemann-Pick disease: ultrastructure of nerve and skeletal muscles. Neurol 25: 107, 1975.

13) Landrieu P, Said G: Peripheral neuropathy in type A Niemann-Pick disease. A morphological study. Acta Neuropathol 63: 66, 1984.

14) Wiehler S, Weissenborn K, Christomanou H: Progradients hirnorganonisches Psychosyndrome mit Erniedringung der Sphingomyelinase-akivatar. Aktuel Neurol 11: 197, 1984.

15) Kikindjanin V, Kleut-Jelie R, Velisavljev M, et al: Selective IgA deficiency associated with Niemann-Pick disease. Allergie u Immunol 30: 46, 1984.

16) Baker HJ, Wood PA, Wenger DA, et al: Sphingomyelin lipidosis in a cat. Vet Pathol 24: 386, 1987.

17) Brier JC: Niemann-Pick disease in a foetus. J Path Bact 66: 471, 1953.

18) Briere J, Calman F, Lagerson A, et al: Maladie de Niemann-Pick de l'adulte suivie de la naisaance a l'age de 26 ans. Forme viscerale pure avec surcharge en sphingomyeline et deficiet en sphingomyelinase. Nouv Rev Franc Hemat 16: 185, 1976.

19) Sogawa H, Horino K, Nakamura F, et al: NiemannPick disease with sphingomyelinase deficiency in two brothers with mental retardation. Europ J Pediatr 128: 235, 1978.

20) Cecil's textbook of medicine, Saunders, Philadelphia London Tront Mexico City Rio de Janeiro Syndey Tokyo, 1982, p568. 